\title{
Interconnected $\mathrm{TiO}_{2}$ Nanowire Networks for PbS Quantum Dot Solar Cell Applications
}

\author{
Fan Xu, ${ }^{1}$ Jaime Benavides, ${ }^{1}$ Xin Ma, ${ }^{1}$ and Sylvain G. Cloutier ${ }^{1,2}$ \\ ${ }^{1}$ Department of Electrical and Computer Engineering, University of Delaware, 140 Evans Hall, Newark, DE 19716, USA \\ ${ }^{2}$ Département de Génie Électrique, École de Technologie Supérieure, 1100 rue Notre-Dame Ouest, Montréal, QC, Canada H3C1K3
}

Correspondence should be addressed to Sylvain G. Cloutier, sylvaing.cloutier@etsmtl.ca

Received 21 November 2011; Revised 7 February 2012; Accepted 15 February 2012

Academic Editor: Sharad D. Bhagat

Copyright ( $) 2012$ Fan Xu et al. This is an open access article distributed under the Creative Commons Attribution License, which permits unrestricted use, distribution, and reproduction in any medium, provided the original work is properly cited.

\begin{abstract}
We present a simple method for the fabrication of an interconnected porous $\mathrm{TiO}_{2}$ nanostructured film via dip coating in a colloidal suspension of ultrathin $\mathrm{TiO}_{2}$ nanowires followed by high-temperature annealing. The spheroidization of the nanowires and the fusing of the loosely packed nanowire films at the contact points lead to the formation of nanopores. Using this interconnected $\mathrm{TiO}_{2}$ nanowire network for electron transport, a $\mathrm{PbS} / \mathrm{TiO}_{2}$ heterojunction solar cell with a large short-circuit current of $2.5 \mathrm{~mA} / \mathrm{cm}^{2}$, a $V$ oc of $0.6 \mathrm{~V}$, and a power conversion efficiency of $5.4 \%$ is achieved under $8.5 \mathrm{~mW} / \mathrm{cm}^{2}$ white light illumination. Compared to conventional planar $\mathrm{TiO}_{2}$ film structures, these results suggest superior electron transport properties while still providing the large interfacial area between $\mathrm{PbS}$ quantum dots and $\mathrm{TiO}_{2}$ required for efficient exciton dissociation.
\end{abstract}

\section{Introduction}

Lead chalcogenide colloidal semiconductor nanocrystals can be promising materials for low-cost, large-area, and efficient photovoltaic devices, due to a large Bohr radius, size-effect tunable bandgap across the near-infrared region and large absorption cross-section, as well as the solution processability [1-7]. Over the last few years, Schottky solar cells based on $\mathrm{PbS}, \mathrm{PbSe}$, or $\mathrm{PbS}_{x} \mathrm{Se}_{1-x}$ quantum dots with power converting efficiency over $3 \%$ have been demonstrated $[3,5$, 7]. More recently, the depleted-heterojunction quantum dots solar cells based on the $\mathrm{PbS} / \mathrm{TiO}_{2}$ nanocrystals have achieved an unprecedented efficiency of $5.1 \%$ [1], and $\mathrm{PbS} / \mathrm{ZnO}$ photovoltaic devices have exhibited excellent air stability for $1000 \mathrm{~h}$ of continuous illumination under ambient atmosphere [2].

In general, the power conversion efficiency of the QDs solar cells is primarily determined by three factors: exciton generation, exciton dissociation, and carrier collection efficiencies. Indeed, it was shown previously that the structure and morphology of the $\mathrm{TiO}_{2}$ layer can play the key role in achieving efficient extraction and transport of minority carriers in dye- and QDs-sensitized solar cells [8]. The $\mathrm{TiO}_{2}$ layer requires large surface areas for quantum dots attaching, as well as rapid electron transport across the film to ensure efficient electron collection by the conductive substrate. The widely used mesoporous $\mathrm{TiO}_{2}$ nanostructured films can be employed to significantly increase the contact area between $\mathrm{TiO}_{2}$ and the active quantum dot layer, thus facilitating exciton dissociation before radiative recombination and allowing efficient carrier collection. However, the electronic transport suffers from slow electron diffusion rates and low electron mobility in the structurally disordered $\mathrm{TiO}_{2}$ mesoporous films $[8,9]$.

Fabrication of $\mathrm{TiO}_{2}$ films from one-dimensional nanowire and nanotube structures has proven to be an effective way to improve the overall efficiencies of the devices [912]. The one-dimensional nanostructure allows diffusion free electron transport along the axial direction to improve electron collection, while the light scattering effect from the subwavelength features can enhance the effective absorption thickness of the quantum dots layer. Nevertheless, one major concern with lateral nanowires is the smaller surface areas it presents for dye and quantum dot sensitization [8].

In this paper, we report the fabrication of superior $\mathrm{TiO}_{2}$ film structures for QD solar cells formed by dip coating and annealing of ultrathin $\mathrm{TiO}_{2}$ nanowire films. This interconnected nanowire network structure maintains the large 
surface-to-volume ratio from traditional porous $\mathrm{TiO}_{2}$ films, while allowing efficient electron transport along the nanowires. As we show, the electron transport and carrier extraction in the $\mathrm{TiO}_{2} / \mathrm{PbS}$ heterojunction solar cell can be significantly improved using this porous interconnected $\mathrm{TiO}_{2}$ nanowire network film. A superb low-cost solar cell was fabricated with a large short-circuit current of $2.5 \mathrm{~mA} / \mathrm{cm}^{2}$, a $V_{\text {oc }}$ of $0.6 \mathrm{~V}$, and a power conversion efficiency of $5.4 \%$ achieved under $8.5 \mathrm{~mW} / \mathrm{cm}^{2}$ illumination.

\section{Experiments}

2.1. Chemicals. Titanium (IV) butoxide 99\% (TBT, Aldrich), oleic acid (90\%, Aldrich), titanium (IV) isopropoxide (TTIP, Aldrich, 99.999\%), poly(acrylic acid) (M 450,000, Aldrich), ethyl acetate (Aldrich, Anhydrous 99.8\%) (EAcAc), ethanol (ACS reagent, $\geq 99.5 \%$ (200 proof, absolute), 1-octadecene (90\%, Aldrich), lead oxide (99.99\%, Aldrich), hexamethyldisilathiane (Fluka) are used.

Preparation of $\mathrm{TiO}_{2}$ Sol-Gel [13]. PAA (0.035 g) and EAcAc $(1.7998 \mathrm{~g})$ were mixed and sonicated at room temperature for 5 minutes. Ethyl alcohol $(42.3429 \mathrm{~g})$ was added and left reposed for 20 minutes. Finally, TBT (13.7489 g) was added to the mixture and was reposed for another 20 minutes, and distilled water $(0.5457 \mathrm{~g})$ was added to start the reaction. The solution was continuously stirred for 8 hours and then aged for 24 hours to form the $\mathrm{TiO}_{2}$ sol-gel.

Synthesis of $\mathrm{TiO}_{2}$ Nanowires [14]. The $\mathrm{TiO}_{2}$ nanowires were synthesized through the nonhydrolytic ester elimination reaction of titanium isopropoxide and oleic acid. TTIP $(3.5 \mathrm{~mL})$ was added to $10 \mathrm{~g}$ of $\mathrm{OA}$ at room temperature under nitrogen atmosphere. The resulting mixture was heated to $280^{\circ} \mathrm{C}$ for a period of $20 \mathrm{~min}$ and was kept at this temperature for $2 \mathrm{~h}$. The light-yellow solution gradually turned dark brown and then white. The solution was then cooled down to room temperature, excess acetone was added, and the solution was centrifuged to precipitate the nanowires.

PbS Quantum Dot Synthesis [15]. Lead oxide (0.45 g), octadecene $(10 \mathrm{~g})$, and oleic acid (1.34 g) are added to a threeneck flask. The mixture is then heated and kept at $80^{\circ} \mathrm{C}$ for two hours under vigorous stirring in vacuum to degas the solution and dissolve the mixture. Then, the temperature is kept at $110^{\circ} \mathrm{C}$ under nitrogen flow for $30 \mathrm{~min}$. Subsequently, a solution made of $210 \mu \mathrm{L}$ of hexamethyldisilathiane diluted in $4 \mathrm{~mL}$ of octadecene is quickly injected into the reaction flask under vigorously stirring. The heating was immediately removed and the reaction solution was allowed to cool down slowly to room temperature. Finally, the colloidal PbS quantum dots are collected by quick injection of the reaction solution into excess amount of acetone (with ratio $\sim 1: 4$ ) for centrifugation. The precipitates are dried in vacuum and redispersed in hexane. To ensure adequate removal of the reaction solvents, precipitation and redispersion are repeated. The quantum dot solution is filtered with $0.2 \mu \mathrm{m}$ polytetrafluoroethylene filters before device fabrication.
Fabrication of Solar Cells. The ITO glass was cleaned using a sequence of ultrasonic baths of deionized water, acetone and isopropanol. Then, the substrate was dipcoated into the $\mathrm{TiO}_{2}$ sol-gel for 10 seconds and then withdrawn at $200 \mathrm{~mm} / \mathrm{min}$ to form a thin layer of planar $\mathrm{TiO}_{2}$ layer $(\sim 35 \mathrm{~nm})$, in order to prevent any shorting of the device. This sol-gel $\mathrm{TiO}_{2}$ layer was annealed at $500^{\circ} \mathrm{C}$ for 1 hour in a tube furnace to improve its crystalline structure and its conductivity. After that, the porous $\mathrm{TiO}_{2}$ layers were fabricated by dip-coating the substrate (immersed in the nanowire solution for 10 seconds, and then withdrawn at $200 \mathrm{~mm} / \mathrm{min}$ ) into the $\mathrm{TiO}_{2}$ nanowires solution in hexane $(\sim 35 \mathrm{mg} / \mathrm{mL})$, followed by another annealing at $500^{\circ} \mathrm{C}$ for 1 hour in the furnace. To make the porous $\mathrm{TiO}_{2}$ layer thicker, another layer of $\mathrm{TiO}_{2}$ nanowire was dip-coated on top and then annealed. The $\mathrm{PbS}$ quantum dots are then deposited using the layer by layer spincoating method [1]. For each cycle, the $\mathrm{PbS}$ quantum dot solution $(25 \mathrm{mg} / \mathrm{mL}$ in hexane) is spin-coated (2000 rpm) on the substrate, then the diluted ethanedithiol solution in acetonitrile $(0.02 \mathrm{M})$ is subsequently spin-coated on top to crosslink the quantum dot and make the quantum dot indissolvable in the original solution, and finally, hexane was spin-coated on the substrate to rinse the quantum dot solid [16]. For both devices, eight layers of quantum dots are deposited. Finally, gold is thermally evaporated on top as the back contact electrode. The solar cell was measured with devices placed on top of an integrated sphere under $8.5 \mathrm{~mW} / \mathrm{cm}^{2}$, white light illumination. The integrating sphere is connected to a fiber illuminator, and the light was uniformly coupled out from the top port of the integrate sphere.

\section{Results and Discussions}

As shown in Figure 1(a) the free-standing $\mathrm{TiO}_{2}$ nanowires are typically $100-200 \mathrm{~nm}$ in length and 3-4 $\mathrm{nm}$ in diameter. As shown in Figure 1(b), the high-resolution TEM analysis of the $\mathrm{TiO}_{2}$ nanowires confirms their sound crystalline structure. The FFT shown in the inset of Figure 1(b) indicates the nanowires are $\mathrm{TiO}_{2}$ anatase, and it was imaged with its [100] direction parallel to the electron beam. Here, the long 18-carbon-atom stabilizing surfactant (oleic acid) plays a crucial role in passivating the nanowires to prevent agglomeration; thus a uniformly and loosely compacted $\mathrm{TiO}_{2}$ nanowires film can be deposited by dip coating the substrate into the nanowire solution, as shown in Figure 2(a).

The $\mathrm{TiO}_{2}$ nanowire fuse with each other at the contact point via sintering. On the other hand, the one-dimensional nanowire will reduce the aspect ratio and spheroidize owing to surface energy reduction [17]. When the spheroidization stops at the contact points of the nanowires, the porous structure is formed. Thus, a high-surface-area, interconnected porous $\mathrm{TiO}_{2}$ nanostructure is fabricated using the facile dip-coating and annealing process, as shown in the SEM image in Figure 2(c). Large quantities of pores are distributed randomly on both the surface and the interior of the $\mathrm{TiO}_{2}$ nanostructure. A high-resolution secondary electron SEM image in Figure 2(d) clearly resolved the porous structure of the film. The irregularly distributed nanopores 


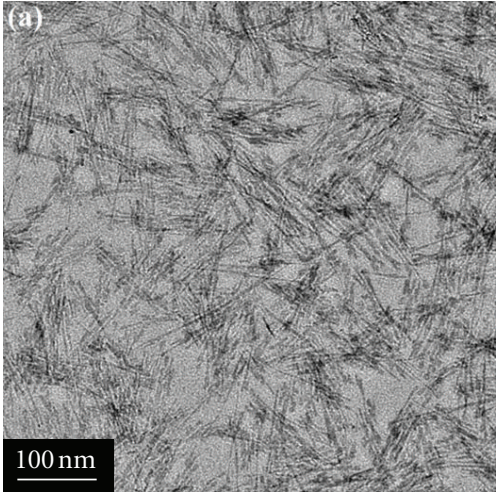

(a)

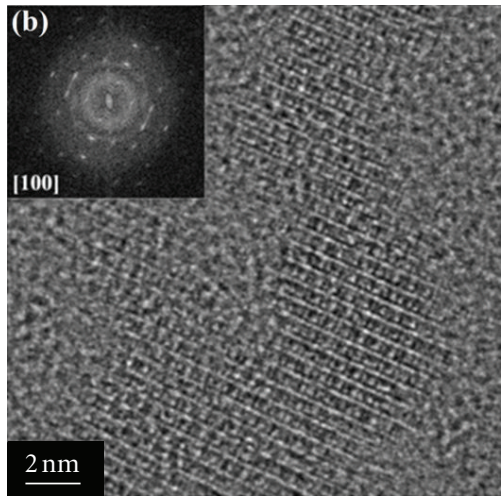

(b)

FIgURE 1: (a) Low-resolution TEM image of the free-standing $\mathrm{TiO}_{2}$ nanowires after synthesis. (b) The high-resolution TEM image of a single ultrathin $\mathrm{TiO}_{2}$ nanowire, the inset shows the corresponding Fast Fourier Transform (FFT) image.

are interconnected by spheroidized NWs after thermal annealing process, with average diameter of $13.2 \pm 4.7 \mathrm{~nm}$ and average pore area of $117 \pm 123 \mathrm{~nm}^{2}$. Since the quantum dots used in these devices are typically 3-4 $\mathrm{nm}$ in diameter, the relatively larger nanopores can create additional volume for QDs attaching, as well as provide large surface areas to achieve efficient electron extraction.

The SEM image in Figure 3(a) shows the structure of the resulting solar cell device, while the band alignment is shown in Figure 3(b). All the fabrication steps except the evaporation are done in ambient atmosphere. The thickness of the planar $\mathrm{TiO}_{2}$ is $\sim 35 \mathrm{~nm}$, the porous $\mathrm{TiO}_{2}$ nanowire layer is $\sim 60 \mathrm{~nm}$, while the $\mathrm{PbS}$ quantum-layer is $\sim 320 \mathrm{~nm}$.

Figure 4 compares the current density-voltage $(\mathrm{J}-\mathrm{V})$ characteristics of a standard $\mathrm{PbS}$ quantum dot-sensitized $\mathrm{TiO}_{2}$ heterojunction solar cell using a planar $\mathrm{TiO}_{2}$ film formed by conventional sol-gel chemistry with the same solar cell using the thick nanoporous interconnected $\mathrm{TiO}_{2}$ nanowire network previously deposited on a thin planar $\mathrm{TiO}_{2}$ film. Here, small $\mathrm{PbS}$ quantum dots of relatively large bandgaps and with their conduction bands well above that of $\mathrm{TiO}_{2}$ were used, so as to achieve efficient electronic transfer from the quantum dots to the $\mathrm{TiO}_{2}$ [18]. For comparison, both the planar and porous $\mathrm{TiO}_{2}$ heterojunction solar cells have equally thick $\mathrm{PbS}$ nanocrystalline layers and both were crosslinked using EDT. In contrast with the planar device, the $\mathrm{TiO}_{2}$ nanowire device exhibits a superb short-circuit current $\left(J_{\mathrm{sc}}\right)$ of $2.5 \mathrm{~mA} / \mathrm{cm}^{2}$, a large open-circuit voltage $\left(V_{\mathrm{oc}}\right)$ of $0.6 \mathrm{~V}$, a fill factor of $33 \%$, and a power-converting efficiency of $5.4 \%$. These results suggest that the large surface area in the porous $\mathrm{TiO}_{2}$ nanostructured film, as well as an efficient carrier transport along the longitudinal axis of $\mathrm{TiO}_{2}$ nanowires, appears to be critical to achieve high $\mathrm{J}_{\mathrm{sc}}$ in the heterojunction solar cell architecture. The near-ideal rectifying $\mathrm{J}-\mathrm{V}$ characteristics of the $\mathrm{TiO}_{2}$ nanowire device under dark directly confirm the formation of a high-quality p-n heterojunction between $\mathrm{PbS}$ and $\mathrm{TiO}_{2}$. In contrast, the planar $\mathrm{TiO}_{2}$ solar cell device suffers from a much smaller short-circuit current $\left(J_{\mathrm{sc}}\right)$, in addition to a significantly lower fill factor of $14 \%$. Moreover, the current drops down rapidly as the voltage starts to increase. Most likely, this can be attributed to the inefficient electron transport in the planar $\mathrm{TiO}_{2}$ layer. Otherwise, it is also possible that pin holes are generated in the planar $\mathrm{TiO}_{2}$ film during annealing, thus ruining the performance of the device and explaining the much larger currents observed under forward bias. Since the open-circuit voltage of the devices is mainly determined by difference of the quasi-Fermi level between the $\mathrm{PbS}$ nanocrystals and the $\mathrm{TiO}_{2}$ layer, both devices exhibit a similar $V_{\mathrm{oc}}$ around $0.6 \mathrm{~V}$.

To better understand the exciton dissociation and electron extraction from the $\mathrm{PbS}$ quantum dots to the $\mathrm{TiO}_{2}$ we studied the absorption and photoluminescence of EDTtreated nanocrystalline films deposited on glass, planar $\mathrm{TiO}_{2}$, and porous $\mathrm{TiO}_{2}$ nanowire network films. Indeed, the electron transfer from small $\mathrm{PbS}$ nanocrystals to the $\mathrm{TiO}_{2}$ can be monitored through the shift and quenching of the absorption and photoluminescence spectra $[19,20]$. The conduction band of the small quantum dots lies well above that of the $\mathrm{TiO}_{2}$ thus the high-energy excitons generated upon the absorption of high-energy photons in small QDs can rapidly dissociate with electrons injected to the $\mathrm{TiO}_{2}$ layer. The porous $\mathrm{TiO}_{2}$ nanowire structure provides large interfacial areas between QDs and $\mathrm{TiO}_{2}$, thus enables efficient electron transfer [21]. This rapid relaxation of high-energy excitons can in turn improve the absorption of high-energy photon by rapid depopulating the excitons in the QDs. As seen in Figure 5(a), the absorption spectrum of the $\mathrm{PbS}$ nanocrystals deposited on porous $\mathrm{TiO}_{2}$ nanowire structure displays a stronger absorption on the high-energy side and an obviously blue shift compared to the QDs deposited on planar $\mathrm{TiO}_{2}$.

Meanwhile, the photoluminescence of the quantum dots is quenched owing to hot electron transfer to $\mathrm{TiO}_{2}$. Figure 5(b) compares the photoluminescence of monolayer of nanocrystals deposited on glass, on planar $\mathrm{TiO}_{2}$ and on the porous $\mathrm{TiO}_{2}$, nanowire network. Due to the photoluminescence quenching at the high energy side, the photoluminescence of the $\mathrm{PbS}$ quantum dots exhibits a $24 \mathrm{~nm}$ red-shift on planar $\mathrm{TiO}_{2}$, compared with a remarkable $76 \mathrm{~nm}$ red shift 


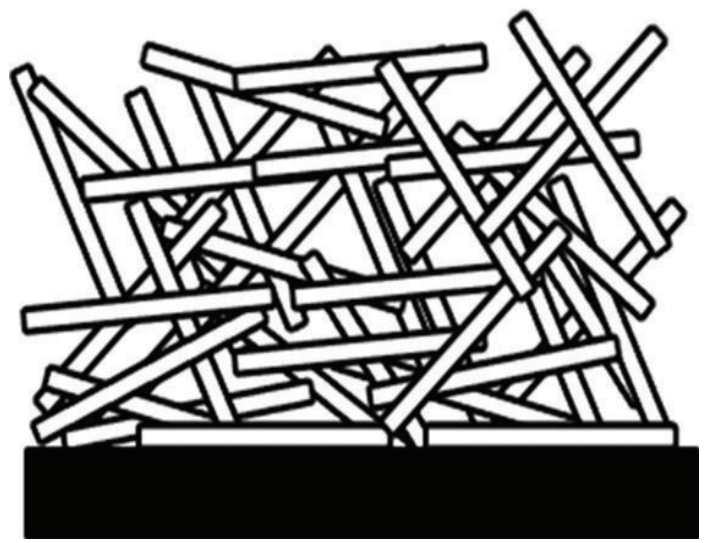

(a)

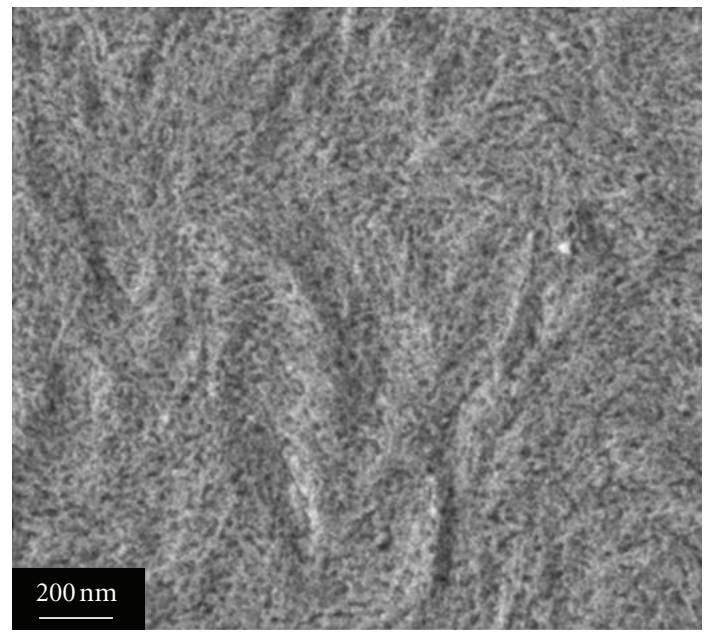

(c)

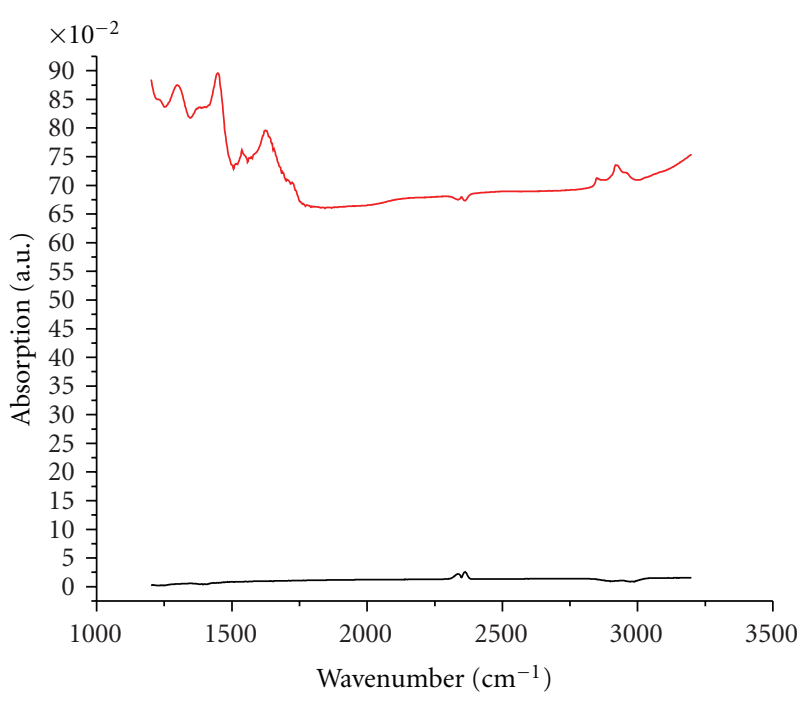

$\mathrm{TiO}_{2}$ nanowires

_ Before annealing

- After annealing

(b)

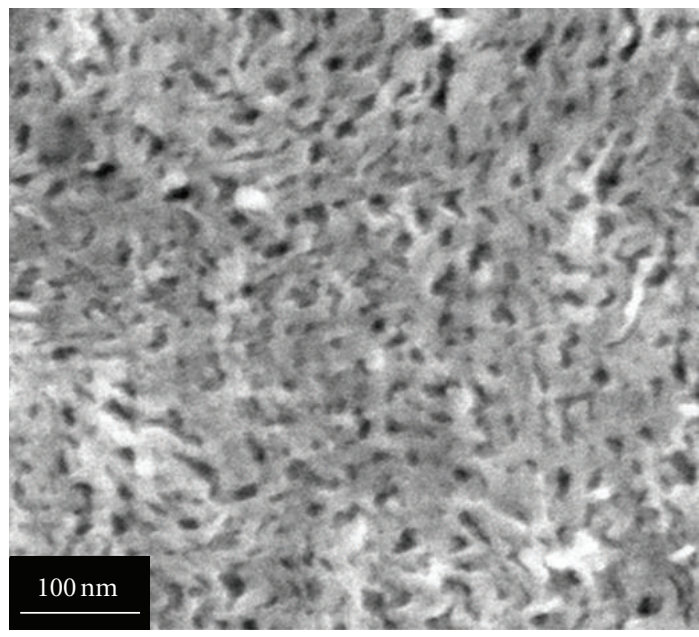

(d)

FIgURE 2: (a) A cartoon showing the loosely packed $\mathrm{TiO}_{2}$ nanowire film fabricated using the dip-coating process. (b) FTIR spectrum of TiO 2 nanowire film dip-coated on a glass slide before and after thermal annealing. (c) $\mathrm{SEM}_{\text {image showing the overview of the porous TiO }}$ nanostructure. (d) High-resolution second-electron SEM image showing the porous interconnected $\mathrm{TiO}_{2}$ nanowire network structure after annealing.

on the porous $\mathrm{TiO}_{2}$ nanowire network film. The strong absorption on the high-energy side combined with the significant quenched and red shifted photoluminescence indicates that efficient electron transfer is achieved between the $\mathrm{PbS}$ quantum dots and the porous $\mathrm{TiO}_{2}$ nanowire. This is also consistent with the superb short-circuit current observed for the porous $\mathrm{TiO}_{2}$ nanowire-based devices owing to its large interfacial areas and strong electron extraction ability.

\section{Conclusions}

In summary, we fabricated a high-performance porous $\mathrm{TiO}_{2}$ film for nanocrystal-sensitized solar cell using an inter- connected $\mathrm{TiO}_{2}$ nanowire network. This facile all-solutionbased method simply relies on dip coating and annealing of ultrathin $\mathrm{TiO}_{2}$ nanowires. This unique nanostructured film provides large interfacial area allowing efficient electron extraction from quantum dots and uses the one-dimensional morphology of the $\mathrm{TiO}_{2}$ nanowires to favor direct electron transport along the long axial direction to improve electron collection. The heterojunction solar cells using this porous interconnected $\mathrm{TiO}_{2}$ nanowire network films exhibit a superb $J_{\mathrm{sc}}$ of $2.5 \mathrm{~mA} / \mathrm{cm}^{2}$, a large $V_{\mathrm{oc}}$ of $0.6 \mathrm{~V}$, and a power conversion efficiency of $5.4 \%$ under $8.5 \mathrm{~mW} / \mathrm{cm}^{2}$ whitelight illumination. Through the absorption and photoluminescence study of the same PbS quantum dots deposited 


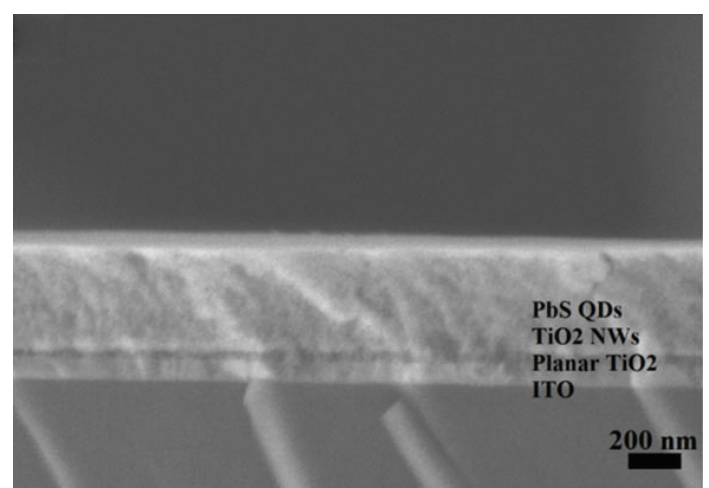

(a)

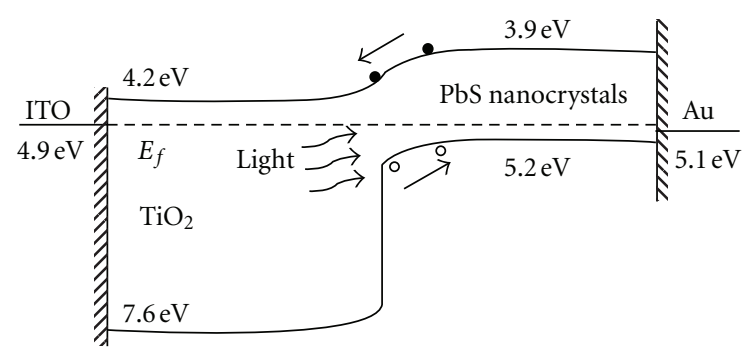

(b)

Figure 3: (a) SEM image showing the cross-section of the $\mathrm{PbS}-\mathrm{TiO}_{2}$ heterojunction solar cell device. (b) Band diagram of the device.

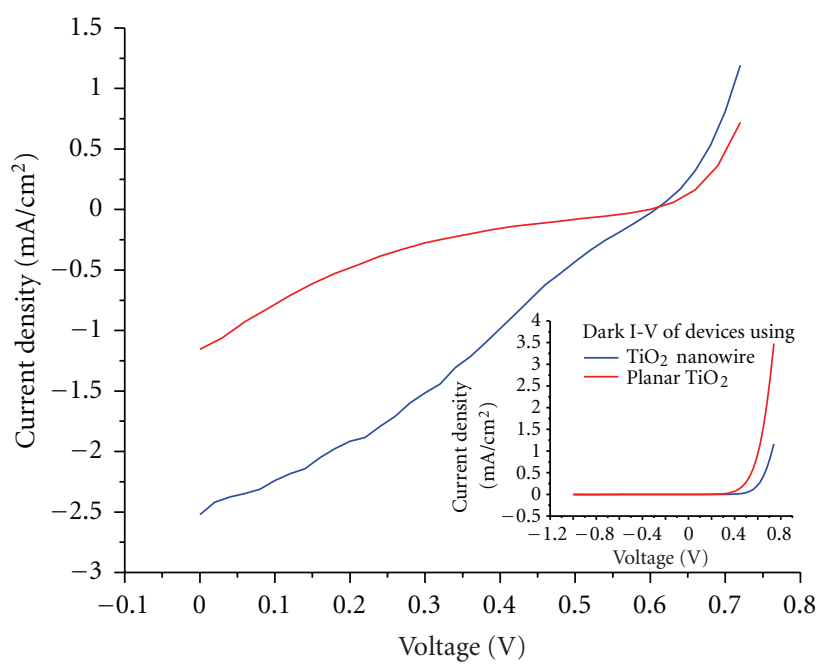

Bright $\mathrm{J}-\mathrm{V}$ of devices using

$-\mathrm{TiO}_{2}$ nanowire

- Planar $\mathrm{TiO}_{2}$

Figure 4: Comparison of the current density-voltage (J-V) characteristics under illumination for a standard $\mathrm{PbS}$ quantum-dotsensitized $\mathrm{TiO}_{2}$ heterojunction solar cell using a planar $\mathrm{TiO}_{2}$ film formed by conventional sol-gel chemistry with the same solar cell using our thick nanoporous interconnected $\mathrm{TiO}_{2}$ nanowire network previously deposited on a thin planar $\mathrm{TiO}_{2}$ film. Both devices are measured under a uniform $8.5 \mathrm{~mW} / \mathrm{cm}^{2}$ white-light illumination. The inset shows the dark I-V characteristics for both devices.

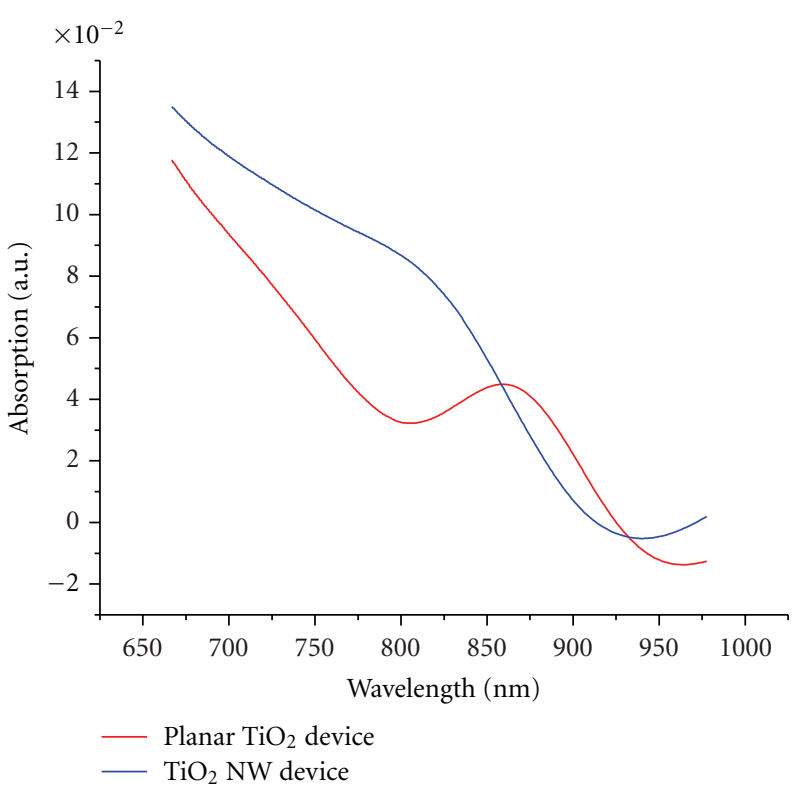

(a)

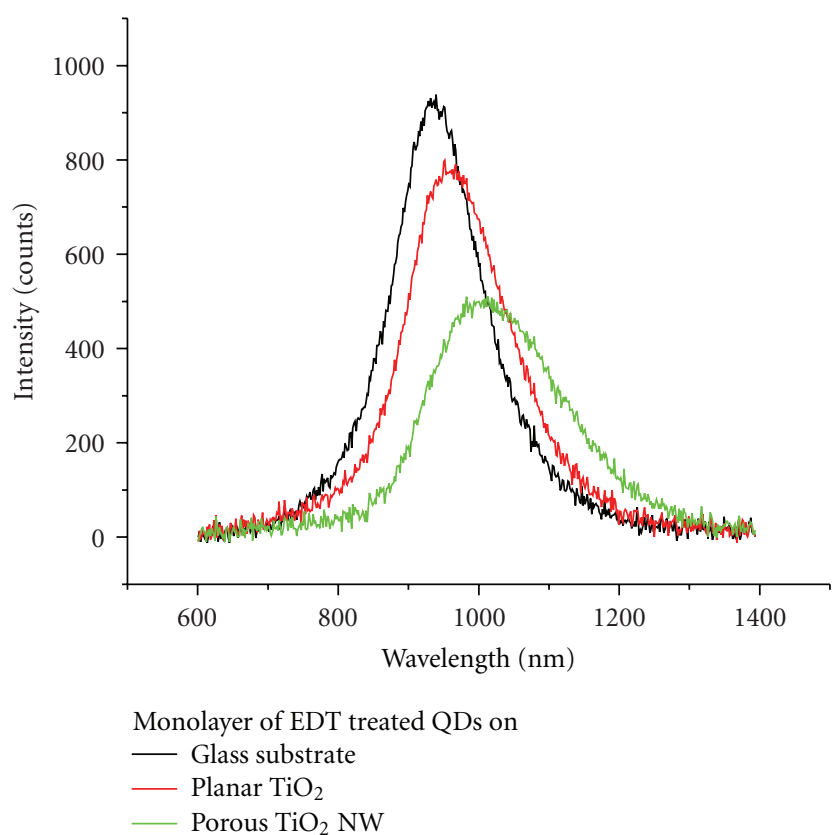

(b)

FIgure 5: (a) Absorption spectrum for the same PbS nanocrystals deposited on planar $\mathrm{TiO}_{2}$ and porous interconnected $\mathrm{TiO}_{2}$ nanowire network film. (b) Photoluminescence from a monolayer of the same EDT-treated PbS nanocrystals deposited on glass, on planar $\mathrm{TiO}_{2}$, on a porous $\mathrm{TiO}_{2}$ nanowire network film.

on various $\mathrm{TiO}_{2}$ substrates, we demonstrated a significantly improved electron-transfer efficiency using the $\mathrm{TiO}_{2}$ nanowire network structure instead of a conventional planar $\mathrm{TiO}_{2}$ film structure. 


\section{Acknowledgments}

The authors would like to thank Sangcheol Kim for the absorption measurements and Xiaoqian Ma for FTIR measurements. This work was supported through the AFOSR (FA9550-10-1-0363), through the DARPA COMPASS Program via a Grant from the DOI NBC (N11AP20031), the DARPA young Faculty Award Program and the ETS Institutional Research Chair Program to whom we are most thankful.

\section{References}

[1] A. G. Pattantyus-Abraham, I. J. Kramer, A. R. Barkhouse et al., "Depleted-heterojunction colloidal quantum dot solar cells," ACS Nano, vol. 4, no. 6, pp. 3374-3380, 2010.

[2] J. M. Luther, J. Gao, M. T. Lloyd, O. E. Semonin, M. C. Beard, and A. J. Nozik, "Stability assessment on a 3\% bilayer PbS/ZnO quantum dot heterojunction solar cell," Advanced Materials, vol. 22, no. 33, pp. 3704-3707, 2010.

[3] J. J. Choi, Y. F. Lim, M. B. Santiago-Berrios et al., "PbSe Nanocrystal Excitonic Solar Cells," Nano Letters, vol. 9, no. 11, pp. 3749-3755, 2009.

[4] T. Ju, R. L. Graham, G. Zhai et al., "High efficiency mesoporous titanium oxide $\mathrm{PbS}$ quantum dot solar cells at low temperature," Applied Physics Letters, vol. 97, no. 4, Article ID 043106, 2010.

[5] J. M. Luther, M. Law, M. C. Beard et al., "Schottky solar cells based on colloidal nanocrystal films," Nano Letters, vol. 8, no. 10, pp. 3488-3492, 2008.

[6] J. Tang, L. Brzozowski, D. A. R. Barkhouse et al., "Quantum dot photovoltaics in the extreme quantum confinement regime: the surface-chemical origins of exceptional air- and light-stability," ACS Nano, vol. 4, no. 2, pp. 869-878, 2010.

[7] W. Ma, J. M. Luther, H. Zheng, Y. Wu, and A. P. Alivisatos, "Photovoltaic devices employing ternary $\mathrm{PbS}_{x} \mathrm{Se}_{1-x}$ nanocrystals," Nano Letters, vol. 9, no. 4, pp. 1699-1703, 2009.

[8] J. Van De Lagemaat, N. G. Park, and A. J. Frank, "Influence of electrical potential distribution, charge transport, and recombination on the photopotential and photocurrent conversion efficiency of dye-sensitized nanocrystalline $\mathrm{Tio}_{2}$ solar cells: a study by electrical impedance and optical modulation techniques," Journal of Physical Chemistry B, vol. 104, no. 9, pp. 2044-2052, 2000.

[9] N. Kopidakis, K. D. Benkstein, J. Van De Lagemaat, and A. J. Frank, "Transport-limited recombination of photocarriers in dye-sensitized nanocrystalline $\mathrm{Tio}_{2}$ solar cells," Journal of Physical Chemistry B, vol. 107, no. 41, pp. 11307-11315, 2003.

[10] B. Liu and E. S. Aydil, "Growth of oriented single-crystalline rutile $\mathrm{Tio}_{2}$ nanorods on transparent conducting substrates for dye-sensitized solar cells," Journal of the American Chemical Society, vol. 131, no. 11, pp. 3985-3990, 2009.

[11] K. Zhu, N. R. Neale, A. Miedaner, and A. J. Frank, "Enhanced charge-collection efficiencies and light scattering in dyesensitized solar cells using oriented $\mathrm{Tio}_{2}$ nanotubes arrays," Nano Letters, vol. 7, no. 1, pp. 69-74, 2007.

[12] A. Guchgait, A. K. Rath, and A. J. Pal, "Near-IR activity of hybrid solar cells: enhancement of efficiency by dissociating excitons generated in PbS nanoparticels," Applied Physics Letters, vol. 9, no. 7, article 073505, 3 pages, 2010.

[13] N. Barati, M. A. F. Sani, H. Ghasemi, Z. Sadeghian, and S. M. M. Mirhoseini, "Preparation of uniform $\mathrm{Tio}_{2}$ nanostructure film on 316L stainless steel by sol-gel dip coating," Applied Surface Science, vol. 255, no. 20, pp. 8328-8333, 2009.

[14] J. Joo, S. G. Kwon, T. Yu et al., "Large-scale synthesis of $\mathrm{Tio}_{2}$ nanorods via nonhydrolytic sol-gel ester elimination reaction and their application to photocatalytic inactivation of E. coli," Journal of Physical Chemistry B, vol. 109, no. 32, pp. 1529715302, 2005.

[15] M. A. Hines and G. D. Scholes, "Colloidal PbS nanocrystals with size-tunable near-infrared emission: observation of postsynthesis self-narrowing of the particle size distribution," Advanced Materials, vol. 15, no. 21, pp. 1844-1849, 2003.

[16] J. M. Luther, M. Law, Q. Song, C. L. Perkins, M. C. Beard, and A. J. Nozik, "Structural, optical, and electrical properties of self-assembled films of PbSe nanocrystals treated with 1,2ethanedithiol," ACS Nano, vol. 2, no. 2, pp. 271-280, 2008.

[17] B. Mukherjee, B. Viswanath, and N. Ravishankar, "Functional nanoporous structures by partial sintering of nanorod assemblies," Journal of Physics D, vol. 43, no. 45, Article ID 455301, 2010.

[18] B. R. Hyun, Y. W. Zhong, A. C. Bartnik et al., "Electron injection from colloidal $\mathrm{PbS}$ quantum dots into titanium dioxide nanoparticles," ACS Nano, vol. 2, no. 11, pp. 2206-2212, 2008.

[19] B. -R. Hyun, A. C. Bartnik, L. Sun, T. Hanrath, and F. W. Wise, "Control of electron transfer from lead-salt nanocrystals to $\mathrm{TiO}_{2}$," Nano Letters, vol. 11, no. 5, pp. 2126-2132, 2011.

[20] I. Robel, V. Subramanian, M. Kuno, and P. V. Kamat, "Quantum dot solar cells. Harvesting light energy with CdSe nanocrystals molecularly linked to mesoscopic Tio 2 films," Journal of the American Chemical Society, vol. 128, no. 7, pp. 23852393, 2006.

[21] W. A. Tisdale, K. J. Williams, B. A. Timp, D. J. Norris, E. S. Aydil, and X. Y. Zhu, "Hot-electron transfer from semiconductor nanocrystals," Science, vol. 328, no. 5985, pp. 1543-1547, 2010. 

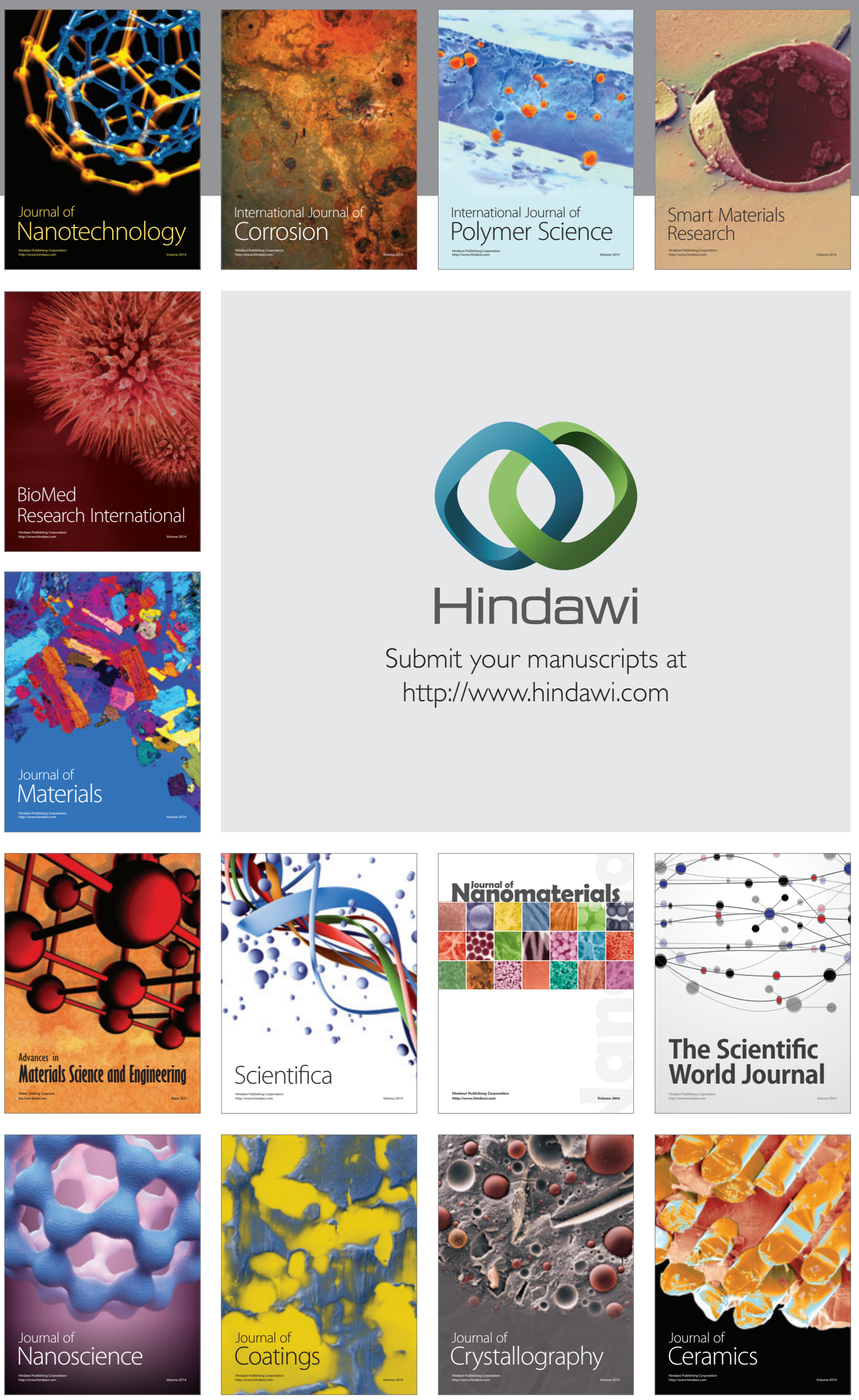

The Scientific World Journal

Submit your manuscripts at

http://www.hindawi.com

\section{World Journal}

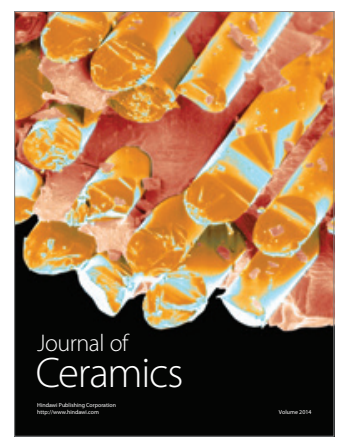

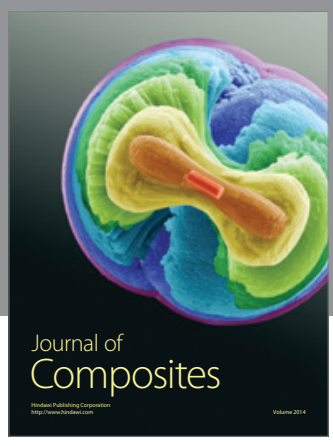
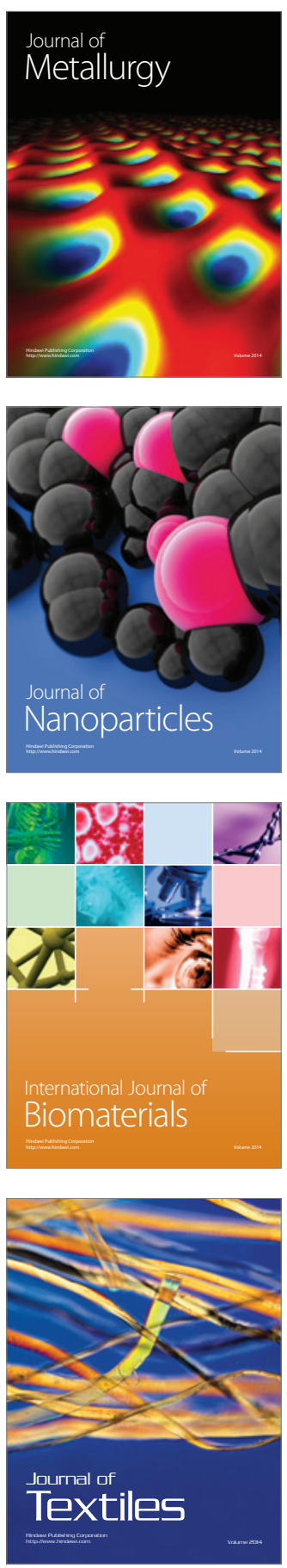